\title{
Infográfico sobre doenças parasitárias negligenciadas para séries iniciais
}

\author{
Ana Jéssily Camargo Barbosa \\ Graduação em Enfermagem e Mestrado em Ensino pela Universidade Estadual do Oeste do Paraná (UNIOESTE). \\ Enfermeira na Prefeitura Municipal de Foz do Iguaçu, PR \\ 凹anajessily@hotmail.com
}

\section{Thais Tânia Ávila}

Graduação em Enfermagem e Mestrado em Ensino pela Universidade Estadual do Oeste do Paraná (UNIOESTE). Enfermeira no Hospital Ministro Costa Cavalcanti, Foz do Iguaçu, PR

\section{Rosane Meire Munhak da Silva}

Graduação em Enfermagem e Mestrado em Biociências e Saúde pela Universidade Estadual do Oeste do Paraná (UNIOESTE). Doutorado em Enfermagem em Saúde Pública pela Escola de Enfermagem de Ribeirão Preto da Universidade de São Paulo (EERP/USP). Docente na Universidade Estadual do Oeste do Paraná (UNIOESTE)

\section{Adriana Zilly}

Graduação em Ciências Biológicas pela Universidade Estadual do Oeste do Paraná (UNIOESTE). Mestrado e Doutorado em Ciências pela Universidade Estadual de Maringá (UEM). Docente na Universidade Estadual do Oeste do Paraná (UNIOESTE)

\section{Reinaldo Antonio Silva-Sobrinho}

Graduação em Enfermagem pela Universidade Estadual do Paraná (UNESPAR). Mestrado em Enfermagem pela Universidade Estadual de Maringá (UEM). Doutorado e Pós-Doutorado na área da

Saúde Pública pela Universidade de São Paulo (USP)

\section{Resumo:}

o presente estudo tem o objetivo de descrever o caminho metodológico utilizado na construção de um infográfico animado, que retrata o tema Doenças Parasitárias Negligenciadas para as séries iniciais de uma escola do município de Foz do Iguaçu-PR, participante do Programa Saúde na Escola. O infográfico foi construído no site Powtoon ${ }^{\circledR}$, um desenvolvedor online gratuito, que disponibiliza recursos de imagem, animação e vídeo. Utilizou-se o Design Instrucional, partindo de uma necessidade de aprendizagem para elaboração de uma solução de aprendizagem, através do Sistema ADDIE, cujas etapas são: Análise, Design, Desenvolvimento, Implementação e Avaliação. A produção do infográfico animado versou sobre doenças parasitárias negligenciadas, pois os professores indicaram ser uma demanda de saúde da escola naquele momento.

Palavras-chave: Serviços de saúde escolar, doenças parasitárias, informática médica, promoção da saúde.

\section{Infographic on negligatory parasitic disorders for initial series}

\begin{abstract}
:
The present study aims to describe the methodological path used in the construction of an animated infographic, which portrays the theme Parasitic Disease for initial series of a school in the city of Foz do Iguaçu-PR, participant in the Health in School Program (PSE). The infographic was built on the Powtoon $^{\circledast}$ website, a free online developer that provides image, animation and video capabilities. It was used the Instructional Design, starting from a learning solution for the elaboration of a learning
\end{abstract}


solution, through the ADDIE System, which is the holder of the evaluation stages: Design, Development, Implementation and Evaluation. The production of the animated infographic faced with a health demand of the school in that moment.

Keywords: School health education, parasitic diseases; medical informatics, health promotion.

\section{Infografía sobre enfermedades parasitarias para los primeros grados}

\section{Resumen:}

Este estudio tiene como objetivo describir el camino metodológico utilizado en la construcción de una infografía animada, que describe el tema Enfermedades parasitarias desatendidas para los grados iniciales de una escuela de la ciudad de Foz do Iguaçu-PR, participante del Programa Salud en la Escuela. La infografía se creó en el sitio web de Powtoon ${ }^{\oplus}$, un desarrollador en línea gratuito que proporciona recursos de imágenes, animación y video. Se utilizó el Diseño Instruccional, partiendo de una necesidad de aprendizaje para la elaboración de una solución de aprendizaje, a través del Sistema ADDIE, cuyas etapas son: Análisis, Diseño, Desarrollo, Implementación y Evaluación. La producción de la infografía animada abordó las enfermedades parasitarias desatendidas y la ciudadanía porque los docentes indicaron que era una demanda de salud escolar en ese momento.

Palabras clave: Servicios de salud escolar, enfermidades parasitarias, informática médica, promoción de la salud.

\section{INTRODUÇÃO}

A escola é um ambiente de construção de pensamento crítico e político, valores, crenças e modos de conhecimento do mundo sendo que estes interferem diretamente na produção social de saúde e representa uma esfera da sociedade aberta a toda a população, tornando-se propícia para o desenvolvimento de práticas de promoção e prevenção à saúde, vislumbrando a participação ativa de indivíduos em seus processos de saúde, dispondo de habilidades para agir em defesa da qualidade de vida (BRASIL, 2011).

Ainda segundo Brasil (2011), o Programa Saúde na Escola (PSE), instituído pelo Decreto Presidencial $n .{ }^{\circ}$ 6.286/2007, através da confluência entre os interesses do Ministério da Saúde e do Ministério da Educação, busca participar da formação de estudantes em sua integralidade, almejando preparo para o enfrentamento das vulnerabilidades a que estão expostas, através de ações de promoção, prevenção e atenção à saúde.

As ações de promoção e prevenção à saúde, trabalhadas no PSE, devem ser desenvolvidas por intermédio de estratégias que estimulem a aprendizagem, assim sendo, o uso de tecnologias e recursos digitais favorecem o envolvimento e participação dos alunos em sala de aula, enriquecendo o processo de ensino-aprendizagem. Alves e Aerts (2011) ressaltam a importância da abordagem simples e contextualizada, instrumentalizando os 
alunos a fazerem escolhas mais saudáveis de vida, ao considerar que as práticas educativas em promoção à saúde fortalecem a capacidade de escolha dos sujeitos.

O uso de tecnologias digitais se faz necessário atualmente e a convivência com estas ferramentas criam a necessidade de adequações em todos os setores da sociedade, inclusive na educação, aliando-se ao que antes era enfrentado como uma distração. As Tecnologias de Informação e Comunicação (TIC's) romperam barreiras e vem reduzindo lacunas, coadjuvando a construção do conhecimento.

A Teoria da Aprendizagem de Mayer et al. (2005) defende diferentes formas de aprender, indicando o infográfico um produto de aprendizagem, uma vez que este engloba conteúdos apresentados por imagens e palavras, tendo como pressuposto o uso de ambas as ferramentas, exigindo força total da cognição, interligando duas formas de aprendizagem, beneficiando-se quanti e qualitativamente.

Existem três categorias de infográficos: estático, interativo e animado. O infográfico animado, aqui escolhido, busca sequenciar linearmente o conteúdo, de maneira progressiva, isto é, tem como objetivo identificar padrões e analisar informações e relações, assim se inicia o processo de construção da mídia digital (BRAGA, 2009; FILATRO; CAIRO, 2015), sendo um meio transformador dos conteúdos, que organiza informações de maneira que o aluno possa compreendê-las (COSTA; TAROUCO, 2010).

Dorneles et al. (2020) relatam que os infográficos no ensino são objetos comuns na atualidade, porém eles já vêm sendo utilizados desde a pré-história como desenhos feitos em paredes de cavernas para melhor comunicação entre os povos, por isso são versáteis, podendo ser simples ou mais estruturados, dependendo da maneira e da perspectiva utilizada.

O presente estudo tem o objetivo de descrever o caminho metodológico utilizado na construção de um infográfico animado, que retrata o tema Doenças Parasitárias Negligenciadas para as séries iniciais de uma escola do município de Foz do Iguaçu-PR, participante do PSE. 


\section{METODOLOGIA}

Trata-se de estudo metodológico com produção tecnológica realizada em 2018. Para colher informações a respeito do funcionamento do PSE no município, os autores optaram por realizar uma visita, a uma escola municipal que aderiu ao programa desde 2017, em Foz do Iguaçu-PR. Buscou-se conhecer o andamento do programa na escola, seu envolvimento com a Unidade de Saúde da Família (USF), onde estava vinculada, e identificar as vulnerabilidades às quais os alunos estavam expostos em conformidade com os eixos de atenção prioritária do PSE.

Tendo como base o levantamento de informações sobre o território, a partir do relato dos professores da referida escola, foram escolhidos dois eixos propostos pelo PSE como prioritários para as ações de promoção a saúde e prevenção de doenças e agravos, sendo eles: "Promoção da Cultura de Paz, Cidadania e Direitos Humanos" e "Identificação de estudantes com possíveis sinais de agravos de doenças em eliminação", estruturando como necessidade de aprendizagem: “Doenças Negligenciadas Parasitárias” (BRASIL, 2011).

O infográfico animado foi construído no site Powtoon ${ }^{\oplus}$, ainda em 2018, em um desenvolvedor online gratuito, que disponibiliza recursos de imagem, animação e vídeo. Utilizou-se o Design Instrucional, partindo de uma necessidade de aprendizagem para elaboração de uma solução de aprendizagem, através do Sistema ADDIE cujas etapas são: Análise, Design, Desenvolvimento, Implementação e Avaliação (FILATRO, 2008).

\section{RESULTADOS}

Inicialmente, na etapa de Análise, foi realizada uma visita a uma escola municipal de Foz do Iguaçu para compreender como era desenvolvido o PSE, levantando observações sobre o envolvimento das equipes de saúde da Unidade Básica de Saúde (UBS) mais próxima, a qual a escola estava vinculada e as vulnerabilidades as quais os alunos estavam expostos. A fase de análise é o primeiro passo para a construção de uma solução educacional, visto que é nela que "são conhecidas as necessidades educacionais propriamente ditas, a caracterização dos alunos e a verificação de restrições" (FILATRO, 2008). Ainda, nesta fase, a partir da coleta de informações, é elaborado um relatório de diagnóstico (BARREIRO, 2016). 
Para a elaboração do relatório de diagnóstico, foi estruturado um instrumento de coleta de dados, com questões a serem respondidas pelos professores da escola, acerca do funcionamento do PSE, isto é, a escolha dos temas de saúde a serem trabalhados, periodicidade das ações educativas, profissionais envolvidos e participação dos alunos e professores. Foram identificados ainda, alguns recursos disponíveis na escola para a utilização dos alunos como: computadores, aparelhos de televisão, DVD e projetor multimídia, além do acesso à internet. A USF do bairro também foi visitada para conhecer a rotina das ações educativas do PSE, cuja coleta de informações ocorreu com a Enfermeira responsável pela Equipe de Saúde da Família.

O relatório foi elaborado sinalizando o público alvo como alunos de seis a 11 anos, que são os sujeitos participantes das ações do PSE desenvolvidas na escola e a demanda de aprendizagem na escola naquele momento eram as parasitoses intestinais.

Após a análise, foi executado o processo de Design, que consiste no "mapeamento e sequenciamento dos conteúdos a serem trabalhados, buscando atender as necessidades educacionais" anteriormente levantadas (FILATRO, 2008). Também, são definidas as estratégias e ferramentas a serem utilizadas durante o processo de aprendizagem, estipulando custos, profissionais envolvidos e cronograma de execução (BARREIRO, 2016).

Para a construção do infográfico animado foram estruturados conteúdos acerca das Doenças Negligenciadas Parasitárias (conceito e agente etiológico) e o Direito ao acesso às condições de prevenção de doenças e ao tratamento (quadro 01).

Em seguida à organização do conteúdo, seguiu-se a etapa de Desenvolvimento, quando devem ser consideradas todas as características/demandas identificadas por meio do públicoalvo, em conjunto com os recursos digitais disponíveis para a produção de um material didático que seja possível de ser utilizado no espaço escolar.

O conteúdo foi produzido no site Powtoon ${ }^{\circledR}$, um desenvolvedor online gratuito, que disponibiliza alguns personagens e recursos de imagem, além de animações e recursos sonoros.

O infográfico foi desenvolvido como um recurso animado utilizando um personagem infantil para narrar os conteúdos estruturados anteriormente. O Theo (nome fictício) foi a personagem criada para tornar o vídeo interessante para os alunos e traz os conceitos já 
elencados no Quadro 01, de maneira sequenciada, estruturada como um bate-papo (figura 1) e tem duração de 2 min e 27 segundos.

Quadro 1 - Detalhamento dos Conteúdos para a construção do Infográfico Animado a partir da demanda indicada pela escola vinculado ao PSE, 2018

\begin{tabular}{|c|c|}
\hline Conteúdo & Detalhamento \\
\hline $\begin{array}{l}\text { Você sabe o que são Doenças } \\
\text { Negligenciadas? }\end{array}$ & $\begin{array}{l}\text { "São aquelas doenças que poderiam ser evitadas, } \\
\text { mas ainda estão presentes em nosso dia a dia." }\end{array}$ \\
\hline Já ouviu falar em Geohelmintos? & $\begin{array}{l}\text { São parasitas que possuem o ciclo de evolução no } \\
\text { solo e alojam-se nos animais ou homem. }\end{array}$ \\
\hline Agora, vamos falar da Esquistossomose. & $\begin{array}{l}\text { É uma doença causada pelo Schistossoma mansoni, } \\
\text { que causa febre, dor de cabeça, fraqueza, diarreia e } \\
\text { até aumento do fígado e baço. }\end{array}$ \\
\hline A Teníase & $\begin{array}{l}\text { É uma doença causada pelo Taenia solium que } \\
\text { parasita o intestino, transmitido ao comer carne } \\
\text { de boi ou porco mal cozida que contenhas as } \\
\text { larvas. Sintomas: diarreia ou prisão de ventre, } \\
\text { enjoo, dor abdominal e cansaço. }\end{array}$ \\
\hline Já a Cisticercose & $\begin{array}{l}\text { Acontece ao ingerir os ovos do Taenia solium que } \\
\text { podem se alojar nos músculos olhos ou cérebro. } \\
\text { Sintomas: dor de cabeça, vômitos e convulsão. }\end{array}$ \\
\hline Ascaridíase ou Lombriga & $\begin{array}{l}\text { É a infecção pelo parasita no intestino. Causa: dor } \\
\text { ou desconforto abdominal, náuseas ou vômitos, } \\
\text { diarreia ou sangue nas fezes, cansaço e presença } \\
\text { de vermes nas fezes. }\end{array}$ \\
\hline Tratamento & $\begin{array}{l}\text { O tratamento é gratuito. Realizar consultas } \\
\text { regularmente e fazer exames solicitados pelos } \\
\text { profissionais de saúde é direito de todo cidadão. } \\
\text { Para prevenir: } \\
\text { 1) Higiene pessoal: lavagem das mãos e banho } \\
\text { diário; } \\
\text { 2) Alimentação saudável: saladas e frutas } \\
\text { higienizadas carnes; bem cozidas; } \\
\text { 3) Qualidade de vida: saneamento básico }\end{array}$ \\
\hline
\end{tabular}

Fonte: os autores.

Figura 1. Theo, personagem criada para apresentar os conceitos no infográfico animado sobre Doenças Parasitárias Negligenciadas (Tela 02), 2018 


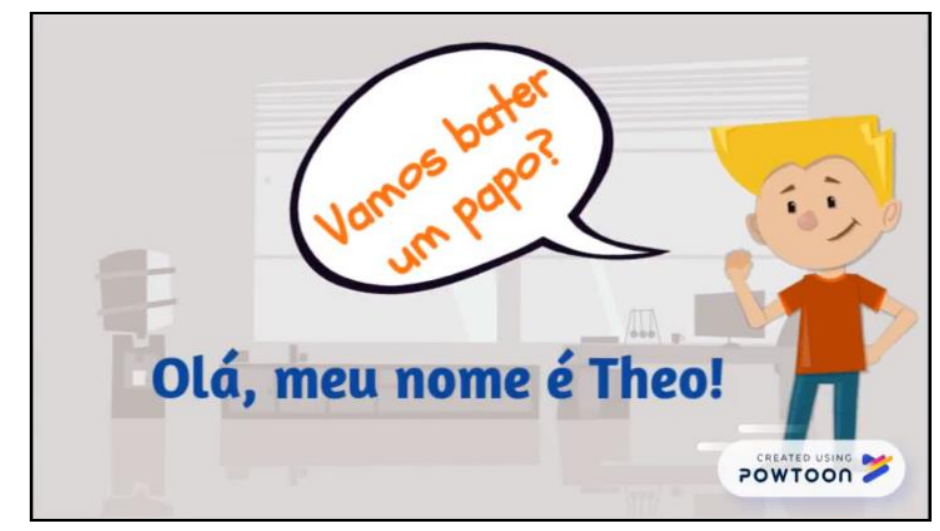

Fonte: os autores.

Foram produzidas 12 telas, sendo que a primeira corresponde à apresentação da personagem. As telas 02 e 03, trazem os conceitos de Doenças Negligenciadas Parasitárias e Geohelmintoses, respectivamente. As parasitoses esquistossomose, teníase, cisticercose e ascaridíase ou lombrigas são apresentadas, com seus agentes etiológicos e os sintomas referentes a cada infecção. As telas 09 e 10 anunciam o direito ao tratamento, a tela 11 traz condições preventivas (figura 2) e a tela 12 apresenta os créditos.

Figura 2. Tela 11 que apresenta ações de prevenção no infográfico animado sobre Doenças Parasitárias Negligenciadas, 2018

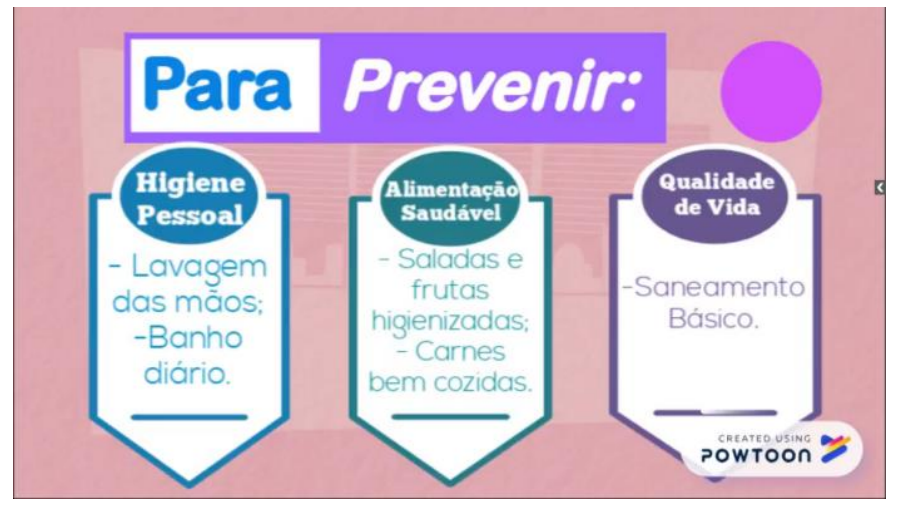

Fonte: os autores.

Seguindo as fases do Sistema ADDIE, a Implementação consiste na disponibilização e execução da ferramenta proposta em ambientes virtuais ou plataformas digitais (FILATRO, 
2008). O infográfico foi ofertado no formato de MP4 no site Youtube, permitindo o acesso gratuito, podendo ser encontrado através de pesquisas que se relacionam com o título do vídeo "Doenças Negligenciadas Parasitárias”.

Por fim, a última etapa é a de Avaliação, que inclui as considerações sobre a efetividade do objeto proposto, reanalisando as estratégias utilizadas para sua produção, bem como a avaliação dos resultados de aprendizagem alcançados, frente aos propostos em primeira instância (FILATRO, 2008). Barreiro (2016) reforça a importância desta fase no processo pedagógico, visto que, a partir desta, é possível identificar potencialidades do objeto de aprendizagem produzido, permitindo melhorias, readequações, redirecionamentos ou reelaborações ao produto.

O infográfico foi avaliado por profissionais da área da saúde, como enfermeiros e biólogos, bem como profissionais das Ciências da Computação e professores da educação básica de ensino. Feito as adequações propostas por estes profissionais, o produto foi inserido na plataforma de vídeos online para então ser apresentado à escola, sendo disponibilizado como recurso didático para utilização em ações de promoção à saúde sobre o tema, disponível de forma gratuita no link

https://www.youtube.com/watch?v=vJrgjlUdnlA, publicado em 16 de julho de 2018.

\section{DISCUSSÃO}

De acordo com Silva-Sobrinho et al. (2017), a educação em saúde é efetiva quando praticada pelos professores e profissionais da saúde, vinculando UBS e o PSE, sendo assim, a necessidade de aprendizagem estruturada baseou-se no fato de que as parasitoses intestinais compõem o grupo de doenças negligenciadas, que possuem maior prevalência em países subdesenvolvidos de clima tropical, como o Brasil (ABREU et al., 2015). Baptista, Ramos e Santos (2013) salientam fatores que contribuem para a alta prevalência destas doenças, como as condições socioeconômicas e a precariedade ou ausência de saneamento básico.

As crianças em idade escolar são mais susceptíveis à infecções e reinfecções de parasitos intestinais, uma vez que, estão mais expostas aos agentes etiológicos, por falhas no 
processo de higiene pessoal (SANTOS et al., 2014). Carvalho (2017) enfatiza a importância da construção de um perfil epidemiológico, cuja análise da presença de doenças parasitárias nesta população, representa uma ferramenta para a estruturação de políticas públicas em saúde que se apropriem desta realidade.

O planejamento de ações relativas ao PSE deve desenvolver também competências que fortaleçam o direito de crianças e adolescentes de participar das decisões que afetam suas vidas e sua saúde (LOPES; NOGUEIRA; ROCHA, 2018), aliando promoção da saúde e cidadania.

O infográfico animado equivale a uma modalidade de objeto de aprendizagem. Braga (2014) apontam alguns atributos técnicos importantes a serem considerados em sua produção. Dentre as características técnicas propostas, salienta-se a Acessibilidade, que consiste na permissão de acesso por diferentes usuários e dispositivos eletrônicos; a Confiabilidade, garantindo conteúdos com fundamentação científica; a Usabilidade facilitando a utilização do objeto de aprendizagem por alunos e professores; além da Reusabilidade, que permite a sua reutilização em diferentes contextos de aprendizagem.

Para Wilson, Mandich e Magalhães (2016), uso de tecnologias favorece a aprendizagem, facilita a compreensão, aumenta o interesse pela busca de conhecimentos e favorece a associação do conteúdo teórico com a prática ao promover diferentes espaços para a aprendizagem que privilegiam a construção do conhecimento e que possuem significados mais envolventes.

Portanto, utilizar o infográfico animado, sendo em smartphone, tablet, computador, notebooks, entre outros, é uma estratégia proveitosa para a aprendizagem (DORNELES et al., 2020).

Diante da realidade encontrada é possível observar a necessidade de incentivo a pesquisas e políticas públicas que melhorem as condições de saúde, principalmente aos grupos vulneráveis, como é o caso das crianças, que estão em fase de desenvolvimento. Políticas como o PSE tem o poder de identificar áreas prioritárias em saúde e fortalecer iniciativas de controle e eliminação de doenças.

Para tanto é necessário estreitar os laços entre a Escola e a Unidade de Saúde da Família, estimulando o desenvolvimento das ações de promoção à saúde, além de intensificar sua atuação, acompanhada de atendimento multiprofissional e capacitação técnica para os 
educandos, nos espaços de educação coletiva, como as escolas, considerando a importância de ações educativas empregando objetos de aprendizagem diversos.

\section{CONCLUSÃO}

Espera-se que a partir da produção do infográfico animado, frente a uma demanda específica de saúde da escola, todos os professores, seja da escola visitada ou de qualquer escolar da rede de ensino, possam utilizá-lo como um objeto de aprendizagem alternativo, a fim de fortalecer a interação com o aluno, auxiliando no processo de ensino-aprendizagem com foco direto para a promoção da saúde.

O Infográfico "Doenças Negligenciadas Parasitárias" foi publicado em 16 de julho de 2018 e está disponível no Youtube, de forma gratuita e em formato de mp4, para acesso gratuito no link https://www.youtube.com/watch?v=vJrgjlUdnlA.

\section{REFERÊNCIAS}

ABREU, A.P.; TESTON, A.P.M.; PAULA, C.A.; RIBAS, A.D. Aspecto epidemiológico das enteroparasitoses em criancas de duas creches em Marialva-PR. Brazilian Journal of Surgery and clinical Research-BJSCR, Cianorte, v. 12, n. 1, p 22-26, 2015. Disponível em:

https://www.mastereditora.com.br/periodico/20150902_224348.pdf Acesso em: 11 de setembro de 2018.

ALVES, G.G.; AERTS, D. As práticas educativas em saúde e a Estratégia Saúde da Família. Ciência \& Saúde Coletiva, v. 16, n. 1, p 319-325, 2011. Disponível em: https://www.scielo.br/scielo.php?pid=S141381232011000100034\&script=sci_abstract\&tlng=pt Acesso em: 11 de setembro de 2018.

BAPTISTA, A.B.; RAMOS, L.S.; SANTOS, H.A.G. Prevalência de enteroparasitoses e aspectos epidemiológicos de crianças e jovens no município de Altamira-PA. Revista Brasileira Pesquisa em Saúde. Osasco, v. 14, p 77-80, 2013. Disponível em: http://www.periodicoseletronicos.ufma.br/index.php/revistahuufma/article/view/2297 Acesso em: 04 de outubro de 2018.

BARREIRO, R.M.C. Um breve panorama sobre o Design Instrucional. Revista Científica em Educação à Distância, Rio de Janeiro, v. 6, n. 2, p. 61-75, 2016. Disponível em: https://eademfoco.cecierj.edu.br/index.php/Revista/article/view/375 Acesso em: 13 de março de 2018.

BRAGA, Juliana Cristina (org.). objetos de aprendizagem volume 1: introdução e fundamentos. Santo André: Editora da UFABC, 2014. Disponível em: https://pesquisa.ufabc.edu.br/intera/wpcontent/uploads/2015/12/objetos-de-aprendizagem-v1.pdf Acesso em: 01 de março de 2018.

BRASIL. Ministério da Saúde. Secretaria de Atenção à Saúde. Passo a Passo PSE: Programa Saúde na Escola. Departamento de Atenção Básica. Brasília: Ministério da Saúde, 2011. Disponível em: 
http://www.gestaoescolar.diaadia.pr.gov.br/arquivos/File/pdf/orientacoes_pse.pdf Acesso em: 10 de agosto de 2018.

CARVALHO, F. F. Prevalência de parasitos intestinais em crianças de idade pré-escolar em Centros Municipais de Educação Infantil em Região de Fronteira - Foz do Iguaçu. № de folhas (65. F.). Dissertação (Mestrado em Saúde Pública em Região de Fronteira) - Universidade Estadual do Oeste do Paraná. Foz do Iguaçu, 2017. Disponível em: http://tede.unioeste.br/handle/tede/3550 Acesso em: 01 de abril de 2018.

COSTA, V. M. D.; TAROUCO, L. M. R. Infográfico: Características, autoria e uso educacional. Novas Tecnologias na Educação, Porto Alegre, v. 8, n. 3, p 1-14, 2010. Disponível em: https://seer.ufrgs.br/renote/article/view/18045 Acesso em 01 de abril de 2018.

DORNELES, L.L.; MARTINS, V.P.; MORELATO, C.S.; GOES, F.S.N.; FONSECA, L.M.M.; CAMARGO, R.A.A. Desenvolvimento de infográfico animado sobre Educação Permanente em Saúde. Rev. Latino-Am. Enfermagem, Ribeirão Preto, v. 28, e3311, $2020 . \quad$ Disponível em: http://www.scielo.br/scielo.php?script=sci_arttext\&pid=S0104-11692020000100368\&lng=en\&nrm=iso Acesso em: 01 de agosto de 2019.

FILATRO, A. Design Instrucional na prática. São Paulo: Pearson Education do Brasil, 2008.

FILATRO, A.; CAIRO, S. Produção de conteúdos educacionais. São Paulo: Saraiva, 2015.

LOPES, I. E., NOGUEIRA, J. A. D., ROCHA, D. G. Eixos de ação do Programa Saúde na Escola e Promoção da Saúde: revisão integrativa. Saúde Debate, Rio de Janeiro, v. 42, n. 118, p 773-789, 2018. Disponível em: https://www.scielo.br/pdf/sdeb/v42n118/0103-1104-sdeb-42-118-0773.pdf Acesso em: 30 de julho de 2020.

MAYER, R. (org). The Cambridge handbook of multimedia learning. New York: Cambridge University Press, 2005. Disponível em: https://www.cambridge.org/core/books/cambridge-handbook-of-multimedialearning/65ED189F0FD10F10A51ADAFF9AE14400 Acesso em: 14 de maio de 2018.

SANTOS, J.; DUARTE, A.R.M.; GADOTTI, G.; LIMA, L.M. Parasitoses intestinais em crianças de creche comunitária em Florianópolis, SC, Brasil. Revista Patologia Tropical. v. 43, n.3, p 332-340, 2014. Disponível em: https://pesquisa.bvsalud.org/portal/resource/pt/biblio-836281

Acesso em: 14 de maio de 2019.

SILVA-SOBRINHO, R.A.; PEREIRA, B.S.A.; TREVISAN, C.L.; MARTINS, F.J.; ALMEIDA, M.L.; MANSOUR, N.R.; CABRAL, P.P.; BEZERRA, R.C.; GRIGNET, R.J. Percepção dos Profissionais da educação e saúde sobre Programa Saúde na Escola. Revista Pesquisa Qualitativa, São Paulo, v. 5, n. 7, p 93-108, 2017. Disponível em: https://editora.sepq.org.br/rpq/article/view/77 Acesso em: 30 de julho de 2020.

WILSON, J., MANDICH, A., MAGALHÃES, L. Concept mapping: a dynamic, individualized and qualitative method for eliciting meaning. Qual Health Res. v. 26, n. 8, p 1151-61, 2016. Disponível em: https://journals.sagepub.com/doi/abs/10.1177/1049732315616623 Acesso em: 25 de julho de 2020.

\section{(c) $\mathrm{EY}_{\mathrm{Y}}$}

Este trabalho está licenciado com uma Licença Creative Commons - Atribuição 4.0 Internacional. 